\title{
LA DISPUTA POR LA CONFIGURACIÓN DE LAS NECESIDADES HABITACIONALES EN LAS POLITICAS PÚBLICAS. CONSTRUCCIÓN DE UN MARCO INTERPRETATIUO PARA SU ABORDAJE
}

ROMAGNOLI, Venettia.

venettiaromagnoli@hotmail.com

Investigadora del Instituto de Investigación y Desarrollo en Vivienda (IIDVi). JTP del Trabajo Final de Carrera TVB de la FAU-UNNE. Becaria posdoctoral del CONICET.

Palabras Clave: Necesidades humanas, políticas habitacionales, marco interpretativo. Keywords: Human needs, housing policies, interpretive framework.

\section{RESUMEN}

Este trabajo se propone exponer los resultados de la construcción del marco teórico de una tesis doctoral dedicada al análisis del proceso de construcción de las necesidades en la Política Federal de Vivienda (20032007), a partir del estudio en profundidad de su aplicación en el AMGR (Chaco, Argentina). El marco interpretativo elaborado - al que se dedicará esta presentación- fue el resultado de la vinculación de las teorías de necesidades humanas y de políticas públicas, realizada a partir de la revisión de los autores que desde diferentes enfoques han aportado al estado del arte de ambas cuestiones y su aplicación al campo del hábitat social y las políticas habitacionales, con el objeto de conformar un corpus conceptual crítico a la luz del cual analizar el mencionado proceso y contribuir al desarrollo de una teoría de necesidades habitacionales básicas multidimensionales consensuadas (NHBMC) como fundamento de una política habitacional integral.

\begin{abstract}
This work proposes to expose the results of the construction of the theoretical framework of a doctoral thesis dedicated to the analysis of the process of construction of the needs in the Federal Housing Policy (20032007), from the study in depth of its application in the AMGR (Chaco, Argentina). The interpretive framework developed was the result of linking the theories of human needs and of public policies made of the review of different authors, who from different approaches have reached to the state of the art of both issues and their application to the field of the social habitat and housing policies. The object is to conform a critical conceptual corpus to analyze the mentioned process and contribute to the development of a theory of multidimensional agreed basic housing needs (Necesidades habitacionales básicas multidimensionales consensuadas. NHBMC) as the fundament of a comprehensive housing policy.
\end{abstract}




\section{OBJETIVOS}

En este punto corresponde distinguir entre el objeto general de estudio de la tesis en el marco de la cual se desarrolló el encuadre teórico que se expone en esta ponencia y los objetivos específicos de esta última. ${ }^{1}$ En relación con la tesis, cabe señalar que estuvo orientada al análisis del proceso de configuración de las necesidades en las políticas habitacionales vigentes en Argentina, con objetivos específicos vinculados con visibilizar dicho proceso como un espacio de disputa entre actores asimétricos, e interpelarlo a la luz de un marco interpretativo crítico. Este trabajo en particular tiene como propósito exponer los principales hallazgos del estudio del estado del arte en torno a las necesidades humanas y las políticas públicas, como así también las propias construcciones conceptuales que se fueron originando en la búsqueda de adecuar e incorporar algunos elementos de esos enfoques generales al marco teórico requerido para el análisis de las necesidades y las políticas habitacionales.

\section{INTRODUCCIÓN O PLANTEO DEL PROBLEMA}

Si bien el tema de las necesidades humanas ha sido ampliamente discutido en el campo de las ciencias sociales desde diferentes áreas que van desde la economía, las ciencias políticas, la teología, etc., en el campo del hábitat social y de las políticas habitacio-

1 La tesis a la que se hace referencia se denomina " ¿Qué vivienda necesitan los pobres? Un estudio sobre la configuración de las necesidades en las politicas habitacionales vigentes a partir de su implementación en el AMGR, Chaco (Argentina)", y fue desarrollada como corolario del cursado del Doctorado en Ciencias Sociales de la Facultad Latinoamericana de Ciencias Sociales (FLACSO) en el marco de una beca doctoral del CONICET, dirigida por el Dr. MIGUEL A. BARRETO. Esta tesis se integró y articuló a un proyecto de investigación apoyado por la Agencia Nacional de Políticas Científicas y Técnicas y por la UNNE (PICTO UNNE 2007-001001) "Instrumentos para la gestión local de una política habitacional integral adecuada a las condiciones de la población en situación de pobreza en el Gran Resistencia", realizado por el Dr. MIGUEL Á. BARRETO (director); la Dra. LAURA ALCALÁ; la Mg. MARÍA A. BENITEZ; la Lic. MARÍA E. FERNÁNDEZ; la Mg. MARTA GIRÓ; la Mg. MARÍA B. PELLI y la Mg. VENETTIA ROMAGNOLI (investigadoras) la becaria de Arquitectura NOEL DEPETTRIS. Tuvo como sede el Instituto de Investigación y Desarrollo en Vivienda (IIDVI) de la FAU-UNNE entre los años 2008 y 2012. nales las necesidades se han considerado como "simplemente dadas", y las discusiones se circunscribieron principalmente a los satisfactores, sin considerar que las necesidades se construyen en un proceso político siempre en disputa, en el cual diversos actores con diferentes cuotas de poder intentan incidir - a través de diferentes mecanismos, recursos o discursospara imponer una interpretación hegemónica.

En las escasas investigaciones en que se ha avanzado sobre el tema de las necesidades habitacionales prevalece una visión sectorial del problema, que señala que las inadecuaciones de las soluciones habitacionales brindadas por la política habitacional radican en el hecho de que en la gestión pública convencional de la vivienda, las necesidades habitacionales son definidas a partir de conjeturas o hipótesis de su naturaleza, más o menos racionalmente fundadas o construidas, o por su traducción como carencia de determinados satisfactores estandarizados o, en el mejor de los casos, por perfiles abstractos de la necesidad basados en aproximaciones estadísticas (PELLI, 2010). Se focalizan las fallas en malas interpretaciones técnicas o la falta de incorporación de la "voz" de los beneficiarios. A partir de entender que este tema requiere un abordaje complejo, este trabajo intenta avanzar en la construcción de un marco interpretativo que permita visibilizar y analizar el proceso de configuración de las necesidades habitacionales, desentrañando las particularidades de ese proceso, los actores que inciden, los intereses que representan, los discursos hegemónicos, las interpretaciones autorizadas, etc., que determinan las definiciones que sustentan la política.

\section{DESARROLLO O RESULTADOS}

Las teorías de necesidades humanas: definición, tipos y proceso de configuración

En el campo de las ciencias sociales, se ha dado un largo y profuso debate científico en torno a las nece- 


\section{Grafico 1. Principales exponentes teóricos de los dos grandes enfoques sobre las necesidades}

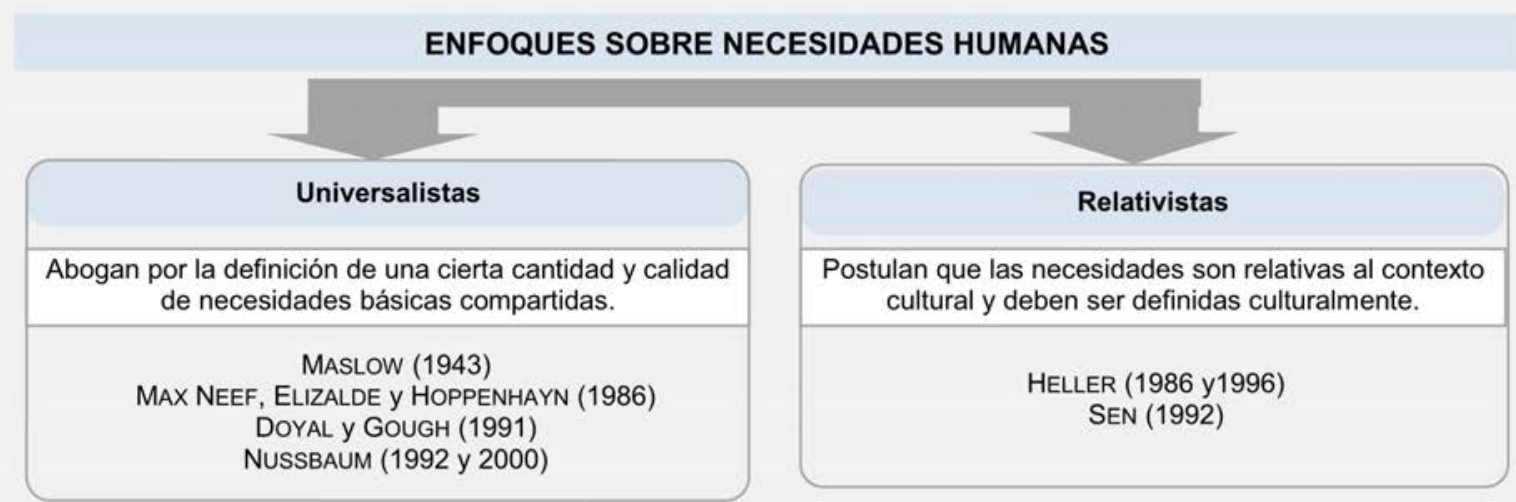

Fuente: elaboración propia

sidades: su definición, carácter y sobre la posibilidad de determinar objetivamente un núcleo irreducible de ellas, y a su vez, si este puede ser definido al margen del desarrollo histórico de cada sociedad. Esta cuestión ha sido extensamente debatida por muchos autores, entre los que se destacan HELLER (1986 y 1996), MAX NEEF, ELIZALDE y HOPENHAYN (1986), DOYAL Y GOUGH (1991, 1994 y 2003, 2008), SEN (1987, 1992, 1997, 2000 y 2003) y NUSSBAUM (1992 y 2002), por mencionar algunos de los grandes referentes de posiciones enfrentadas sobre el tema. Los diversos abordajes resultantes pueden agruparse, en una primera instancia, en dos grandes polaridades: por un lado, las que identifican las necesidades básicas con los estados subjetivos y relativos de carencias y, por otro, las que entienden a las necesidades como un fenómeno objetivo, posible de ser generalizado. (PEREIRA, 2002: 47). A su vez, dentro de los autores que promueven la definición de necesidades universales (MASLOW, 1943; MAX NEEF, ELIZALDE y HOPPENHAYN, 1986; DOYAL y GOUGH, 1991; NUSSBAUM, 1992 y 2000, entre otros), algunos han avanzado en el desarrollo de taxonomías más desagregadas con base conceptual en la perspectiva de los derechos humanos.

En cuanto a los "tipos de necesidad", varios de los autores han avanzado en la distinción o clasificación de las necesidades desarrollando en algunos casos - principalmente los precursores de las posiciones universalistas - taxonomías con diferentes grados de desagregación y resolución. Uno de los primeros antecedentes puede encontrarse en MASLOW (1943), quien en el marco de su teoría psicológica de las necesidades definió una jerarquía de las necesidades humanas. Por su parte, HELLER (1978 y 1986), representante del neomarxismo y defensora del relativismo cultural en relación con la definición de las necesidades, propone distinguir entre las "necesidades existenciales" (ontológicamente primarias, fundadas en el instinto de autoconservación) y las "necesidades propiamente humanas" (no regidas por el impulso natural); señala que en el seno de estas últimas se encuentran además las "necesidades alienadas" (propias del capitalismo: poder, dinero, posesión). Planteó además la existencia de necesidades cuantitativas y cualitativas, e introduce la categoría de "necesidades radicales" para referirse a aquellas que no se integran al capitalismo y que se desarrollan en forma contradictoria dentro de ese modo de producción con el objetivo de superar la estructura de "necesidades necesarias" del orden burgués y producir la revolución (HELLER, 1986: 179).

MAX NEFF, ELIZALDE y HOPPENHAYN (1986) realizan un aporte significativo al campo de las necesidades humanas, ya que plantean la distinción entre "necesidades", "satisfactores", "bienes" y "medios". Desde esta perspectiva, las necesidades humanas se diferencian epistemológica y metodológicamente de sus satisfactores. (MAX NEFF, ELIZALDE y HOPPENHAYN, 1986: 16-17). Con base en ese postulado proponen una taxonomía desagregada de necesidades y satisfactores como instrumento de política y de acción. ${ }^{2}$ Los autores señalan, además, que los ataques a las teorías universales de necesidades por parte de los defensores del relativismo cultural se deben al error conceptual de asimilar necesidades a satisfactores, en la medida en que las primeras son las mismas en todas las culturas y en todos los tiempos, mientras que los segundos cambian al ritmo de la historia y se diversifican de acuerdo con las culturas y las circunstancias.

De manera coincidente con los postulados de MAX NEEF ET ÁL. (1986), DOYAL Y GOUGH (1991) plantean que las necesidades son universales, mientras

\footnotetext{
2 La matriz presenta nueve necesidades básicas: subsistencia, protección, afecto, entendimiento, participación, ocio, creación, identidad y libertad, conectadas con cuatro categorías de satisfacción de necesidades: ser, tener, hacer e interacción. Se obtiene una matriz de 36 campos en donde a los satisfactores positivos se contraponen los pseudosatisfactores o satisfactores inhibidores, que ofrecen una falsa satisfacción (MAX NEFF, ELIZALDE y HOPPENHAYN, 1986: 25-30).

3 Las necesidades básicas consisten en las precondiciones universales que permiten la participación en la propia forma de vida (GOUGH, 2003: 23). Su definición se sustenta en KANT, quien postula que para que los individuos actúen y sean responsables deben tener capacidad mental y física para hacerlo (DOYAL y GOUGH, 1991, citados por GROPPA, 2004: 7).
} 
que los satisfactores son variables, y proponen una primera distinción entre "necesidades básicas" ${ }^{3}$ y "necesidades intermedias".

Las primeras son entendidas como precondiciones universales: "salud física" y "autonomía de agencia" 4 , y en un segundo nivel, la "participación críti$\mathrm{ca}{ }^{5}$, que requiere para su realización "autonomía crítica"; mientras que las "necesidades intermedias" son las características universales de los satisfactores que contribuyen a mejorar la salud física y la autonomía, y se agrupan en once categorías. Todos estos elementos se articulan y constituyen una taxonomía que tiene por objeto la formulación de un patrón universal desde una perspectiva de derechos humanos (GOUGH, 2003: 23-27).

SEN, otro de los grandes referentes del tema, a diferencia de las propuestas teóricas de DOYAL Y GOUGH y MAX NEFF, nunca formuló un elenco exhaustivo de capacidades ni las justificó materialmente, de manera de contar con un criterio general de evaluación. Sin embargo, realizó un aporte significativo al plantear el pasaje de la "necesidad" a la "capacidad", y proponer una distinción entre las "capacidades", los "funcionamientos" y los "bienes primarios". El primer concepto se refiere a las opciones asequibles a una persona, entre los cuales puede elegir lo que razonablemente valora; los funcionamientos son las realizaciones (capacidades de ser o hacer elegidas por cada individuo), mientras que los bienes primarios son convertidos - mediante su uso- en algo valorado. Este factor de conversión depende a su vez de las capacidades y situación de las personas (SEN, 1987, 1992, 1997, 2000, SEN y FOSTER, 2003 citados por GROPPA, 2004: 3).

4 Es la capacidad de decidir informados sobre lo que debe hacerse y sobre cómo debe ser hecho (GOUGH 2003: 23)

5 Es la capacidad de situar la forma de vida en la que uno fue criado, criticarla y actuar para cambiarla si fuera necesario (GOUGH, 2003: 23).

6 Esta taxonomía puede compararse con el modelo de las necesidades humanas de DOYAL y GOUGH (1994). Tanto es así que el mismo GOUGH en un texto denominado "El enfoque de las capacidades de M. Nussbaum: un análisis comparado con nuestra teoría de las necesidades humanas" se dedica a exponer los puntos en común de ambos enfoques (GOUGH, 2007: 177-202).
NUSSBAUM (2002), tomando como base la teoría de capacidades de SEN, propone un elenco de capacidades básicas con las que debería contar todo ser humano ${ }^{6}$, que debería servir de fundamento a "principios básicos que las garantías constitucionales deberían suscribir" en cualquier nación del mundo. ${ }^{7}$ (NUSSBAUM, 2002: 112).

Otros aportes que nutrieron en los últimos años el debate sobre las capacidades están vinculados con las críticas suscitadas por un supuesto "sesgo individualista" de algunos de los enfoques reseñados precedentemente, y dieron lugar al surgimiento de diversas propuestas teóricas que pretenden superar las limitaciones detectadas, a partir de la incorporación de la dimensión colectiva del bienestar. Estos desarrollos - a decir de sus precursores - ofrecerían las bases para elaborar estrategias de desarrollo humano cuyo objetivo sea la consecución de logros de desarrollo humano colectivo. (DUBOIS MIGOYA, 2008: 35). Entre los principales exponentes que impulsaron la incorporación de la dimensión social de las necesidades al estado de la cuestión se encuentran ROBEYNS (2004), NEUHOUSER (2005), NELSON (2004), GASPER y VAN STAVEREN (2003) y la misma NUSSBAUM (2002 y 2003), STEWART (2005) IBRAHIM (2006) y DENEULIN (2006)

GASPER (2002) propone hablar de "capacidadesS" (por skills, habilidades, y substantive, sustantivas) y "capacidades-O" (por opciones y oportunidades) (GASPER, 2002). Por su parte, GOUGH (1991) integra a su enfoque teórico el carácter social de las necesidades, y contempla dentro de la taxonomía descripta precedentemente las denominadas "pre condiciones societales"; mientras que NUSSBAUM (2002) plantea distinguir entre "capacidades básicas, internas y combinadas". Las capacidades internas se refieren a aquellos estados personales que son "suficientes para el ejercicio de las funciones requeridas"; las capacidades combinadas son capacidades internas combinadas con "las condiciones externas apropiadas" para el ejercicio de la función (GROPPA, 2004: 6) 
"En el campo teórico de las necesidades, FRASER (1989 y 1991) realiza uno de los aportes más significativos, ya que propone reorientar el debate en torno a las "políticas de necesidades" y "distribución de satisfactores" hacia las "políticas de interpretación de las necesidades"

DUBOIS MIGOYA (2008) propone recuperar conceptos existentes, tales como "Bienes Públicos" y "Capital Social", ${ }^{8}$ y aprovecharlos en la construcción de una teoría de las necesidades que supere sesgos individualistas, en cuanto sean compatibles con el desarrollo humano (DUBOIS MIGOYA, 2008: 50-54; 61). Otros autores plantean la necesidad de crear nuevas categorías teóricas. STEWART (2005) plantea la existencia de "capacidades grupales", definidas como el promedio de las capacidades de los individuos que forman el grupo. Para IBRAHIM (2006) las "capacidades grupales" son generadas a través del compromiso que las personas asumen en la acción colectiva para conseguir el tipo de vida que consideran valioso. Por su parte, DENEULIN (2006) introduce dos categorías conceptuales: las "estructuras de vida común" para designar a los bienes colectivos y la "agencia sociohistórica", que le permite confrontar la "agenda individual" con las limitaciones y posibilidades que ofrece la realidad histórica (DUBOIS MIGOYA, 2008: 58-60).

En el campo teórico de las necesidades, FRASER (1989 y 1991) realiza uno de los aportes más significativos, ya que propone reorientar el debate en torno a las "políticas de necesidades" y "distribución de satisfactores" hacia las "políticas de interpretación de las necesidades" (FRASER, 1991: 5). Fundamenta este enfoque enfatizando que muchas de las teorías sobre necesidades son "básicas", debido a que no intentan desenredar las redes que se establecen en el proceso de configuración y reconocimiento de una necesidad, y evitan así problematizarlas. Para esta autora, todo análisis de las necesidades humanas debe asumir los siguientes supuestos: a) las necesidades no pueden ser tomadas como "simplemente dadas"; la interpretación de las necesidades se realiza en un espacio político siempre en disputa (entenderlo de esta manera permite analizar la dimensión interpretativa de las políticas de satisfacción de necesidades, puesto que lo que está en contienda y en debate no solo son los satisfactores, sino también la interpretación política de las necesidades); b) el hecho político en cuestión es quién logra establecer definiciones sustantivas y autorizadas (desde que perspectiva, con qué intereses, etc.) y c) las formas socialmente aceptadas del discurso público disponible para reconocer determinadas necesidades están sesgadas a favor de los grupos sociales dominantes y que, por lo tanto, van en detrimento de los grupos subordinados $u$ opuestos (FRASER, 1989: 7).

\section{LAS TEORÍAS DE POLITICAS PÚBLICAS}

PEREIRA señala que "no hay servicios sociales sin la delimitación de aquellas necesidades que deben ser satisfechas" (PEREIRA, 2002: 46). Siguiendo a esta autora, en la actualidad, vivimos en una fase de la historia de la protección social en la cual las referencias a las necesidades sociales constituyen un criterio de primer orden en la toma de decisiones. Consecuentemente, el concepto de necesidades (su noción y real contribución a la formulación de políticas públicas) ha suscitado interés analítico crítico por parte de los sectores intelectuales y políticos no conservadores (PEREIRA, 2002: 46). En esta misma dirección, GOUGH (2003) advierte que las necesidades humanas de encuentran inevitablemente presentes en los discursos y prácticas sobre el bienestar social. Desde este enfoque -en un mundo crecientemente mercantilizado, donde la globalización financiera tiene consecuencias económicas, políticas y culturales de variado impacto y en donde el espacio de los estados nacionales para hacer política se ve restringido-, las políticas sociales deben intentar resolver las tensiones entre las "necesidades de las personas" y las "necesidades del

7 La teoría de las capacidades de NUSSBAUM intenta fundamentar la universalidad de su propuesta en dos niveles: por un lado, tomando como base el desarrollo de las virtudes por Aristóteles y el imperativo categórico kantiano; por otro, apelando a una experiencia de diálogo intercultural que realizó en la India entre 1997 y 1998 (GROPPA, 2004: 11).

8 Desde esta perspectiva resultan "bienes colectivos" aquellos que son centrales para el bienestar de las personas individuales, y entiende al "capital social" como un compromiso compartido de valores sociales que se expresan en la cantidad y calidad de las relaciones sociales, que exige la dimensión interpersonal (DUBOIS MIGOYA, 2008: 51-54) 
capital" (GOUGH, 2003: 32). Pero esta intermediación que deben realizar las políticas sociales entre las necesidades humanas y los sistemas socioeconómicos no es nueva. Para KRMPOTIC (1999) la relación entre necesidades humanas y políticas públicas viene ligada a la modernidad, y se inicia a partir de la desvinculación de los Estados del poder de las iglesias y el reconocimiento de las necesidades como objeto de acción de aquellos (KRMPOTIC, 1999: 18-19).

Varios autores (SUBIRATS, 1989; TAMAYO SÁEZ, 1997) han reconocido el carácter cíclico del proceso de la política pública. ${ }^{9}$ Desde estos enfoques se postula que el ciclo seguido por toda política se inicia cuando un gobierno asume y define la existencia de un problema para proponer alguna solución, analiza alternativas en función de los intereses implicados y los recursos disponibles, se fija determinados objetivos y toma las decisiones que desencadenan la implementación de acciones, para obtener ciertos resulta- dos (ver gráfico 2). Sin embargo, este proceso no es estrictamente técnico ni aséptico; por el contrario, el escenario de las políticas públicas es un espacio de disputa de actores en el cual estos se movilizan según intereses en pos de incidir en el proceso a través de la utilización de todo tipo de recursos, en donde el Estado asume un rol protagónico por su poder de legitimación de las decisiones. En este sentido, se entiende, a partir de BOURDIEU (1993), que la autoridad es la capacidad del Estado para modular su imagen en función de una serie de valores sociales y expectativas comunes. En esta misma dirección, JOBERT (2004) señala que las políticas públicas son herramientas del Estado para la conformación, regulación y legitimación de grupos sociales y, al mismo tiempo como acciones, resultado de la pugna y negociación de actores colectivos dentro del aparato estatal, que generan transformaciones en la realidad social conducentes al cambio o al mantenimiento del orden establecido (ver gráfico 3).

Gráficos 2 y 3. Ciclo de la política pública y politicas públicas como producto del Estado imbricado con la sociedad

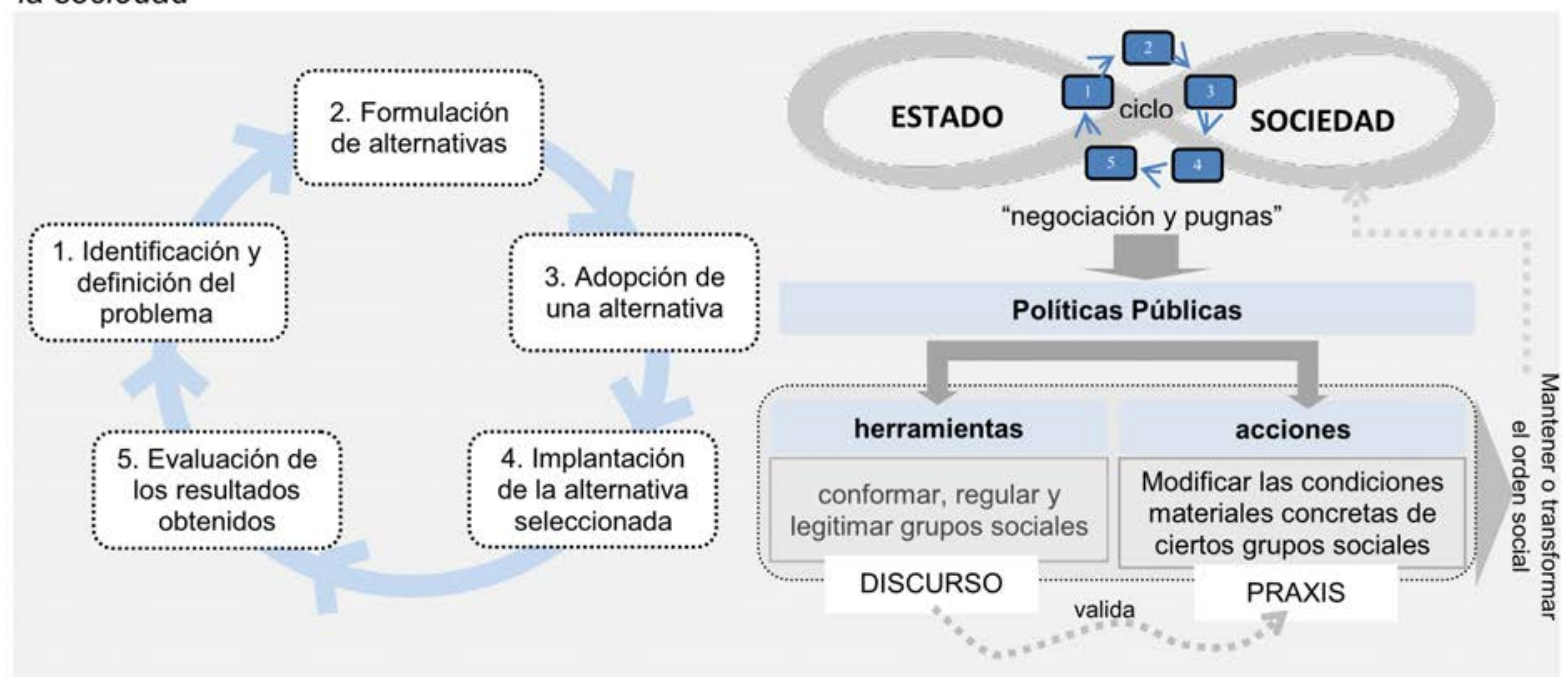

Fuente: elaboración propia sobre la base de TAMAYO SÁEZ (1997: 2) Fuente: elaboración propia sobre la base de PÉREZ BRAVO (2010) 
"La concepción histórica y hegemónica de la "vivienda social pública" presenta una íntima relación con la percepción del problema y su consecuente abordaje desde la política habitacional."

\section{Del concepto de "vivienda social pública" a la construcción de un concepto de necesidades habitacionales desde un enfoque multidimensional}

La concepción histórica y hegemónica de la "vivienda social pública" presenta una íntima relación con la percepción del problema y su consecuente abordaje desde la política habitacional. Para BARRETO ET ÁL. (2014), el punto de partida es la concepción más prevaleciente del "satisfactor" mediante el cual la política habitacional argentina de las últimas décadas dio respuestas a las necesidades habitacionales de los sectores de bajos recursos. Esta concepción entiende a la vivienda como un objeto físico acabado, asociado con una parcela de suelo (vivienda individual), producido de manera serial y estandarizada (por empresas constructoras), para grupos de destinatarios anónimos (hogares individuales) que no participan del proceso de decisiones y a los que se adjudican las viviendas terminadas en propiedad. Para esta concepción, la "vivienda adecuada o digna" (consagrada como derecho social en la Constitución Nacional) es un objeto físico que debe reunir una serie de cualidades constructivas y de instalaciones, así como tener determinados tipos de espacios y una cantidad de cuartos según la composición del hogar que la habita (BARRETO ET ÁL., 2014). Es mucho lo que se ha analizado y debatido sobre esta forma de concebir la vivienda social. Su significado, obviamente, tiene profundas implicancias ideológicas y especialmente económicas, que la reafirman como mercancía y la aíslan de sus relaciones sociales y territoriales, ya que se trata de una concepción fuertemente condicionada por los intereses de ciertos sectores económicos y políticos, en cuyo peso radican los principales obstáculos para modificar esta concepción de la "vivienda social pública" que fundamenta la política habitacional que finalmente se termina implementando.

9 Cabe señalar que el ciclo o proceso de las políticas públicas es una construcción conceptual. No todas las políticas públicas siguen este proceso en todas sus fases, e incluso con frecuencia algunas alteran el orden del proceso (TAMAYO SÁEZ, 1997: 2).
Sin embargo, existe una larga trayectoria de aportes teóricos en el campo del hábitat social que desde un posicionamiento crítico al concepto de "vivienda social pública" han propuesto nociones contra-hegemónicas. Ente los principales referentes de estas perspectivas pueden mencionarse las contribuciones de PELLI (2007), YUJNOVSKY (1984), BARRETO Y ALCALÁ (2007), BARRETO ET ÁL. (2014), por mencionar algunos. Para YUJNOVSKY (1984), la vivienda debe ser entendida como una "configuración de servicios habitacionales" que debe dar respuestas a "necesidades humanas primordiales": albergue, refugio, protección ambiental, espacio, vida de relación, seguridad, privacidad, identidad, accesibilidad física, entre otras. Aclara - desde un enfoque relativo- que ellas varían en cada sociedad y grupo social y se definen en el devenir histórico (YUJNOVSKY, 1984: 18). Esta forma de definir a la vivienda implica superar su concepción físico-material y económica desde donde se la considera en términos de stock. Por su parte, PELLI (2007) desarrolló detalladamente el conjunto de funciones que "la vivienda urbana moderna" —entendida desde este enfoque como convención social general de la vivienda adecuada - debe dar como respuestas para satisfacer las necesidades habitacionales: a) de relaciones, privacidad, intimidad y pudor; b) de higiene, sanidad y pulcritud; c) de protección y seguridad; d) sobre reducción o eliminación de esfuerzos o molestia física en la vida dentro de la vivienda y en la operación de sus elementos y requisitos de pertenencia a un sistema territorial de hábitat social, entendido como la conexión con un conjunto de redes tangibles de servicios e intangibles de localización y pertenencia (PELLI: 155-174).

En trabajos anteriores (BARRETO ET ÁL., 2014), recuperando parte de las formulaciones de los autores reseñados, se avanzó en desarrollos conceptuales en virtud de contribuir al estado de la cuestión, a partir de la introducción de la noción de "multidimensionalidad del problema habitacional" y la consecuente necesidad de "integralidad en su abordaje". Este en- 


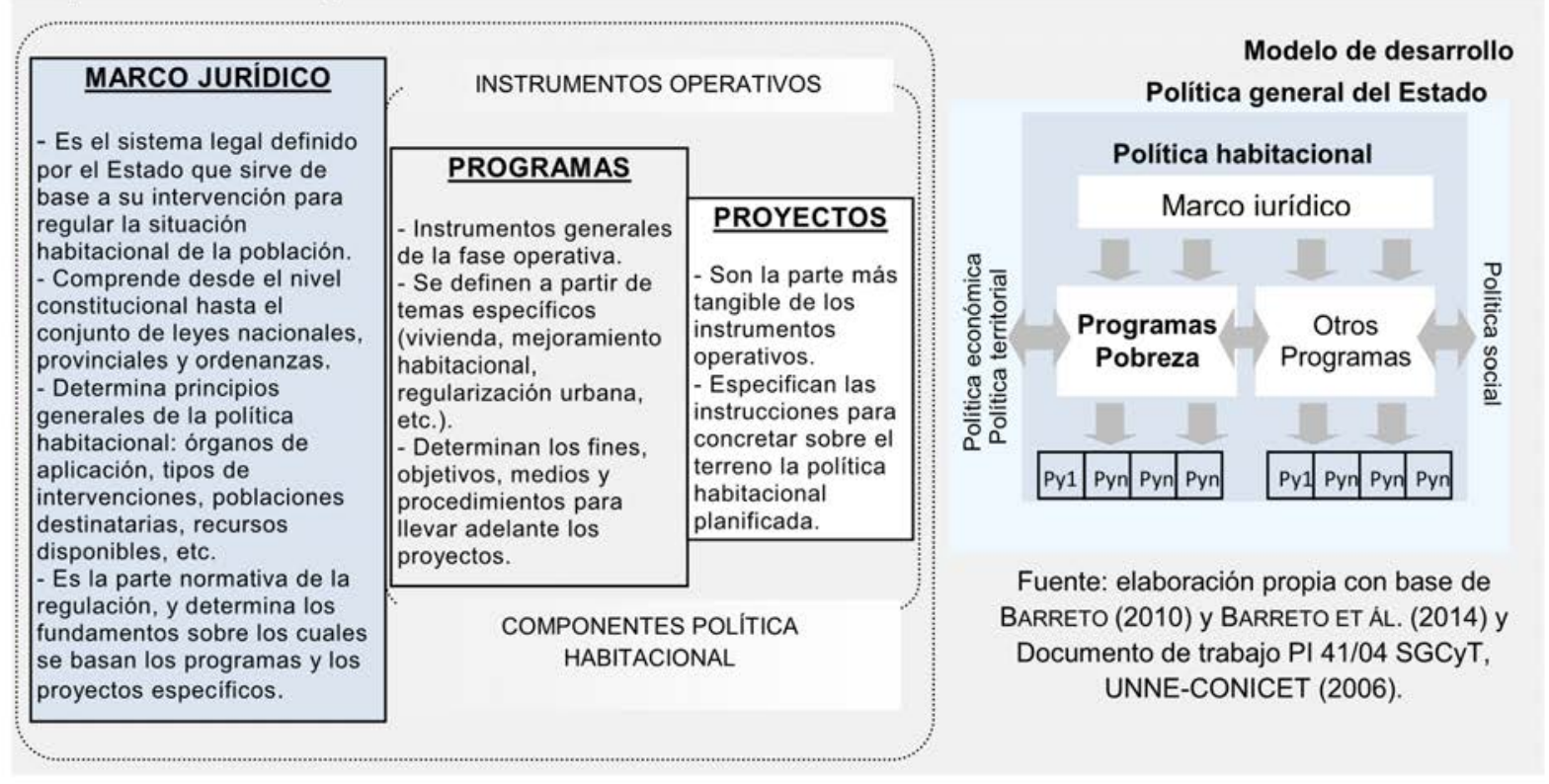

foque se sustenta en la concepción fundamental de que las necesidades habitacionales, como basamento de una política habitacional, deben formularse en relación con las necesidades del habitar en su conjunto, de modo que su satisfacción por parte de la política habitacional debe ser pensada siempre como una parte de la resolución integral del habitar adecuado, lo que implica superar la concepción de la pobreza solamente como un problema económico y entenderla como un problema complejo y multidimensional, especialmente en los hogares que viven en situaciones críticas, ya que se encuentran inmersos en un proceso estructural que en muchos casos los afecta hace mucho tiempo. En la mayoría de los casos es de transmisión intergeneracional, y tiene raíces económicas, sociales, culturales, ambientales, políticas, etc., en las que intervienen múltiples aspectos, que se encuentran íntimamente relacionados entre sí y conforman un círculo de reproducción de las condiciones de vida que torna muy específica su reversión, porque al estar relacionados entre ellos se inciden mutuamente. De este modo, el problema habitacional de los hogares en situaciones de pobreza crítica debe concebirse desde la perspectiva del hábitat en su conjunto.

\section{LA POLÍTICA HABITACIONAL}

De acuerdo con BARRETO (2010) y BARRETO ET ÁL. (2014), se entiende la política habitacional como las intervenciones directas de organismos del Estado de distintas jurisdicciones —realizada desde determinadas orientaciones políticas - en la producción habitacional, para facilitar el acceso a soluciones habitacionales consideradas "dignas" o "adecuadas" para sectores de la población que, por causas de ingresos insuficientes, no pueden acceder a ellas a través del mercado formal, y que en el caso de Argentina, sa- tisfacen inadecuadamente sus necesidades habitacionales a través de diferentes estrategias individuales o colectivas: mediante procesos autogestionarios de producción informal (autoconstrucción, construcción por encargo, compra, alquiler u ocupación) de tierras y viviendas precarias en áreas degradadas o sin servicios, o mediante hacinamiento familiar, o pagando para habitar en lugares precarios (inquilinatos, hoteles-pensiones, etc.), o habitando directamente en lugares públicos. Se entiende además que la política habitacional está compuesta por un marco jurídico y sus instrumentos operativos: los programas y los proyectos (ver gráfico 4).

Se concibe, por otra parte, que la política habitacional es solo una parte de las políticas sociales y territoriales implementadas por los gobiernos, que comprenden muchos otros aspectos, como los de la salud, la educación, la seguridad, el trasporte, etc., o las infraestructuras y equipamientos correspondientes, y el contenido de aquellas y sus relaciones siempre se encuentran condicionados por la orientación del modelo de desarrollo impulsado por cada gobierno, y de manera más general por el modelo de sociedad deseable que estos aspiran alcanzar (ver gráfico 5). Debido a este motivo, la comprensión del problema habitacional y las definiciones de su abordaje desde una política habitacional son indisociables de la orientación del modelo de desarrollo y el modelo de sociedad que promueven los distintos gobiernos (BARRETO ET ÁL., 2010).

\section{MARCO INTERPRETATIVO PROPIO}

Sobre la base de la revisión del estado del arte, se precisan en esta sección algunas posiciones y concep- 


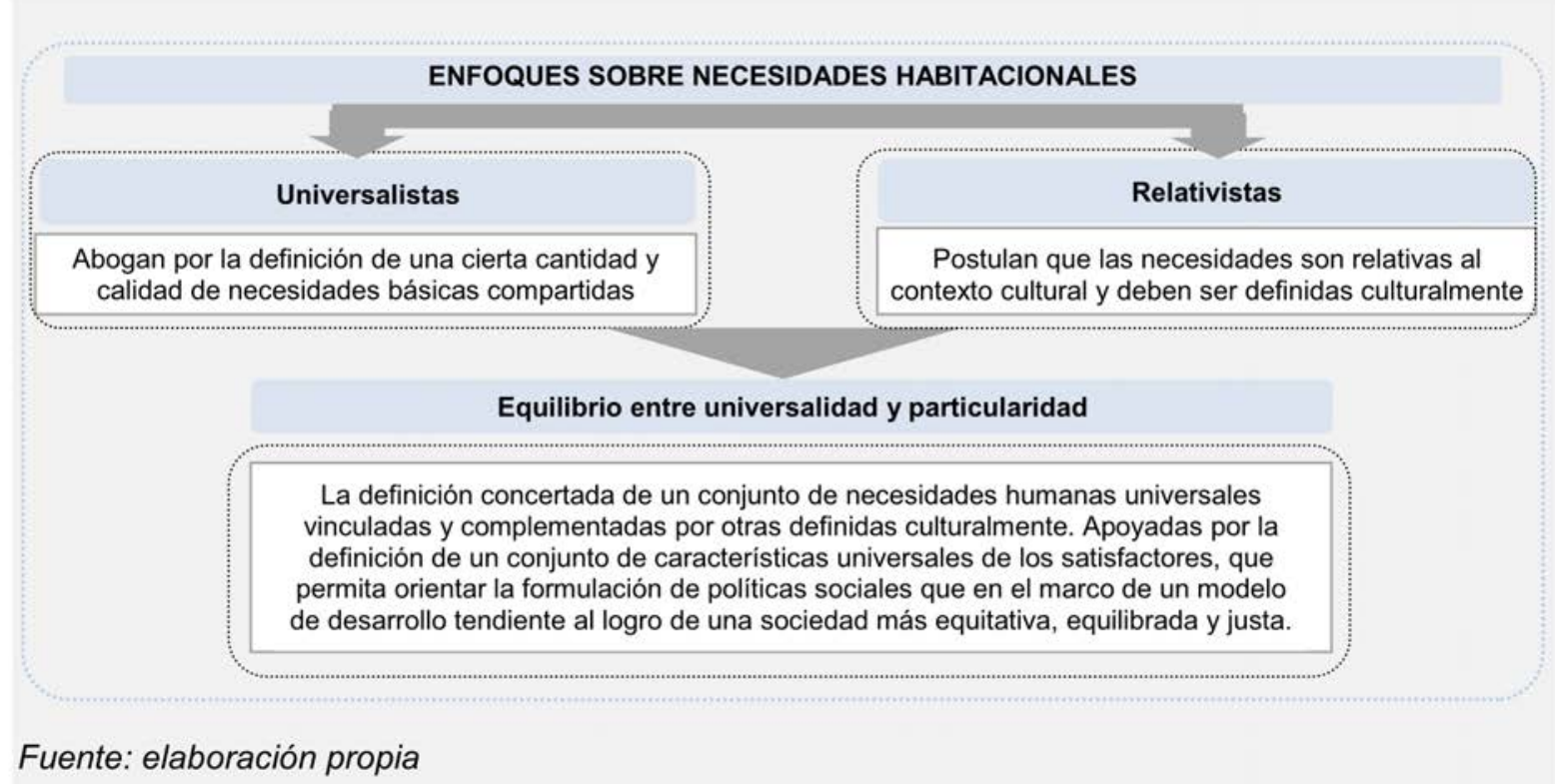

tos que fueron recuperados para la construcción de un marco interpretativo propio. En primer lugar, con respecto a las dos grandes posiciones enfrentadas en relación con las necesidades (universalistas vs. relativistas), se propone un tercer enfoque (ver gráfico 6) -que si bien puede reconocer su génesis en los aportes teóricos de DOYAL Y GOUGH (1991) y GOUGH (2003) al referirse a las "precondiciones de procedimientos o políticas" - cuya conceptualización no ha sido aún adecuadamente desarrollada.

Gráfico 7. Relación teórico-metodológica entre los momentos del proceso de configuración de las necesidades y los niveles de la politica

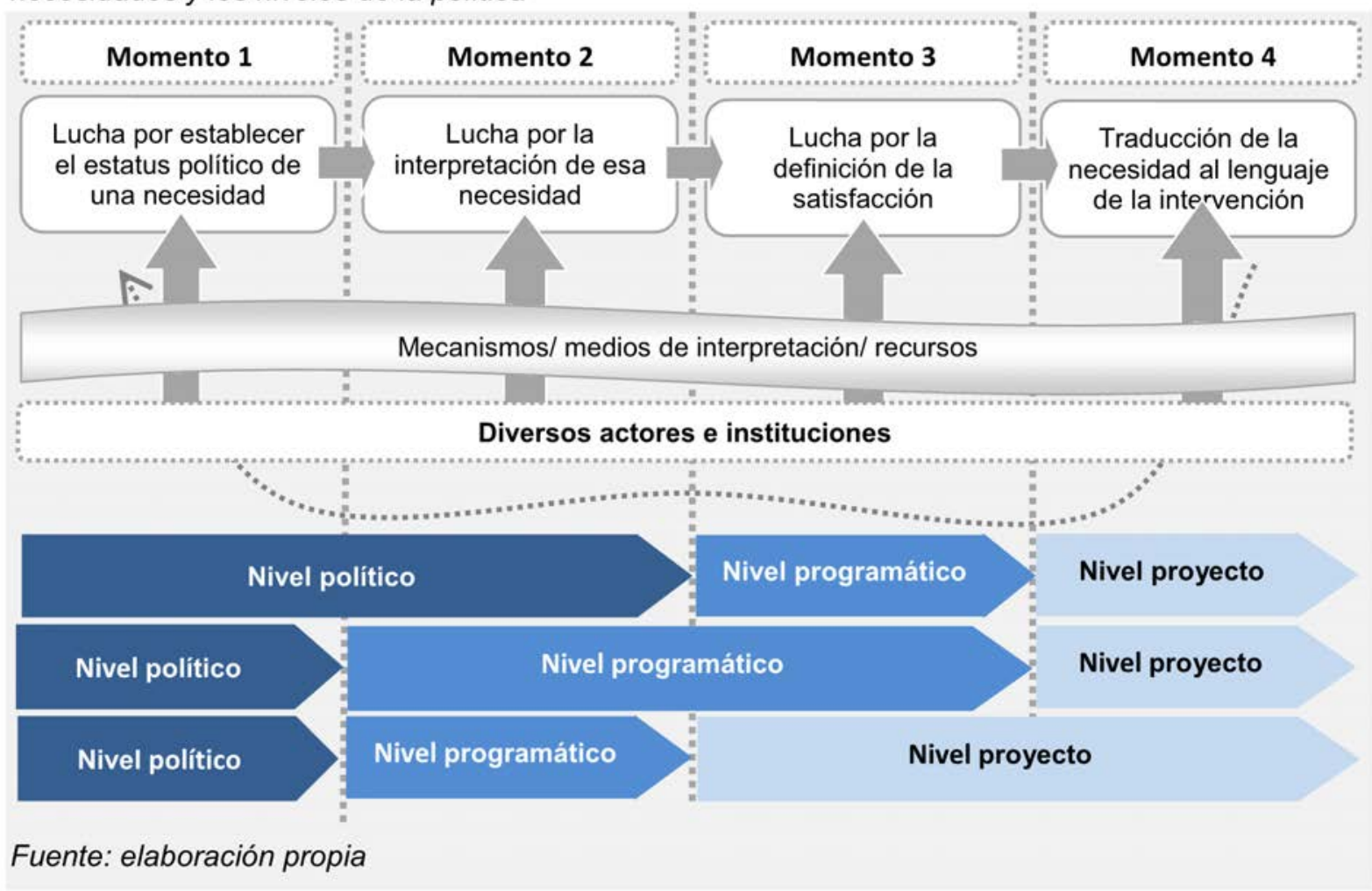


En relación con la discusión en torno al uso de los conceptos de "necesidades" vs "capacidades", se adopta el primer concepto, por su afinidad con la perspectiva de los derechos humanos, aunque se recupera el énfasis puesto en el aspecto potencial que implica toda necesidad de la teoría de SEN. Se entiende además que las necesidades humanas se diferencian epistemológica y metodológicamente de sus satisfactores, y que cambian lentamente, mientras que los satisfactores se modifican de una forma más vertiginosa y contextual a través del tiempo y de las culturas, y que existen además diferentes tipos de satisfactores: violadores, pseudosatisfactores, inhibidores, singulares y sinérgicos. Finalmente, en relación con los satisfactores, se considera que el concepto de "características universales de los satisfactores" de DOYAL Y GOUGH (1991) resulta más adecuado para el enfoque que se postula en este trabajo, ya que permitiría respetar la diversidad cultural y contextual desde un enfoque universal de necesidades.

Otro de los aportes fundamentales para la construcción del marco interpretativo de necesidades adecuado a una teoría del hábitat integral es la consideración de la dimensión social de las necesidades. En este sentido se construye la categoría de "necesidades grupales", entendiéndolas como aquellas generadas a través del compromiso que las personas asumen en la acción colectiva para conseguir el tipo de vida que consideran valiosa.

En cuanto a la definición de las necesidades y los satisfactores, se comparte con FRASER (1991) y KRMPOTIK (1999) que las necesidades no están "simplemente dadas", sino que se construyen en un proceso de disputa entre actores asimétricos que utilizan los recursos con los que cuentan para tratar establecer o monopolizar la definición autorizada y legítima. En este proceso el Estado asume un rol protagónico, al constituirse en términos de BOURDIEU (1993) en el poseedor de un meta-capital que le permite, a través de las políticas púbicas, conformar, regular y legitimar grupos sociales conducentes al cambio o al mantenimiento del orden establecido.

A partir del reconocimiento de la existencia de un "proceso de construcción de las necesidades" FRASER (1991) y del "proceso o ciclo de las políticas públicas" (TAMAYO SÁEZ, 1997; SUBIRTAS, 1989 y JONES, 1984), se avanzó con fines analíticos en la construcción de un esquema que integra ambos enfoques y recupera los diferentes momentos que estos procesos atraviesan, con el objetivo de contribuir a su visibilización, y para relacionarlos a su vez con los diferentes y niveles de la política habitacional (nivel general de la política, de los programas y de los proyectos). Se plantea además que las políticas habitacionales, de acuerdo con el modelo de desarrollo y los lineamientos que propicien, pueden ser "enlatadas"10, y dejar pocos espacios de discusión para su definición en los niveles jurisdiccionales inferiores, o pueden ser más "flexibles", y permitir la introducción de mayores definiciones en las instancias de los programas y los proyectos. Esta cuestión resulta clave al vincular la política con el proceso de configuración de las necesidades habitacionales, ya que los actores, recursos e intereses que participan en los distintos momentos podrán pertenecer o incidir en diferentes niveles jurisdiccionales, tal como se expresa en el gráfico 6 .

En virtud de clarificar el concepto de política habitacional integral y sobre la base de los aportes teóricos analizados en el campo del hábitat social y las políticas habitacionales de los autores reseñados, y de un conjunto de lineamientos de una política habitacional integral desde un abordaje multidimensional —desarrollado en investigaciones previas como integrante de un equipo mayor (BARRETO ET ÁL., 2014)_, se sintetiza a continuación el posicionamiento a la luz

10 Si bien este término ha sido utilizado por varios autores -FERNÁNDEZ WAGNER (2007), BARRETO y ROMAGNOL (2008): ROMAGNOLI (2012) — para hacer referencia a la implementación de programas habitacionales exógenos financiados por entidades de crédito internacional (BM, BID, etc.), en este caso se hace referencia genérica a cualquier política habitacional, especialmente a sus instrumentos (programas y proyectos) que definen de manera rígida una secuencia de utilización de recursos, servicios e insumos, y dejan pocos intersticios que permitan la inclusión de otros actores en los procesos decisorios. 
Cuadro 1. Lineamientos de una política habitacional integral

\begin{tabular}{|c|c|}
\hline \multicolumn{2}{|r|}{ Lineamientos de una política habitacional integral } \\
\hline 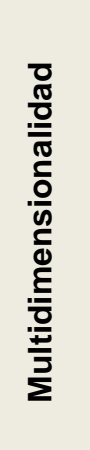 & $\begin{array}{l}\text { El problema habitacional de estos hogares no puede ser reducido solamente a los aspectos } \\
\text { materiales de la vivienda (tal como se tiende a conceptualizarla habitualmente, y en especial } \\
\text { desde las políticas sectoriales, que se basan en los estudios oficiales del déficit habitacional), sino } \\
\text { que tiene que ser definido teniendo en cuenta todos los aspectos que afectan sus condiciones } \\
\text { de vida. Esto implica que todos los elementos que componen el problema no pueden ser } \\
\text { descompuestos en aspectos aislados, para ser abordados de forma independiente, sino que } \\
\text { deben ser considerados a partir de las relaciones que los interdefinen, concibiéndolos como } \\
\text { dimensiones de un único problema, prestando atención a las características de las relaciones } \\
\text { que se establecen y la contribución o afectación que entre ellos se produce, para que estas } \\
\text { condiciones resulten adecuadas o no. }\end{array}$ \\
\hline 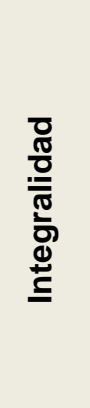 & $\begin{array}{l}\text { El abordaje del problema habitacional tiene que darse en un marco de actuación integral. Si } \\
\text { bien la intervención de una política habitacional integral tendrá siempre por objetivos centrales } \\
\text { el mejoramiento de los aspectos físicos de las viviendas, los barrios o áreas de proyectos } \\
\text { especiales, es imprescindible que aborde este aspecto del problema de forma relacionada con } \\
\text { los otros factores que hacen a las condiciones de vida, teniendo en cuenta cómo ellos se inciden } \\
\text { y retroalimentan mutuamente. Esto puede lograrse a través de la articulación de políticas, en } \\
\text { pos de conseguir el mejoramiento equilibrado. El abordaje de cada una de las dimensiones del } \\
\text { problema tiene que contribuir con la solución de los demás, según las incidencias e } \\
\text { interdefiniciones existentes. }\end{array}$ \\
\hline 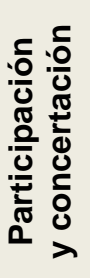 & $\begin{array}{l}\text { La política habitacional debe brindar posibilidades e instancias efectivas de participación, } \\
\text { mediante acciones estructuradas de promoción para la concertación en la toma de decisiones } \\
\text { en sus distintos niveles y fases de la política. Es fundamental que esta participación promueva } \\
\text { un equilibrio en la representación de los diferentes sectores económicos y sociales organizados } \\
\text { de la sociedad, con acciones especiales de promoción en aquellos sectores afectados } \\
\text { generacionalmente por la pobreza estructural. }\end{array}$ \\
\hline 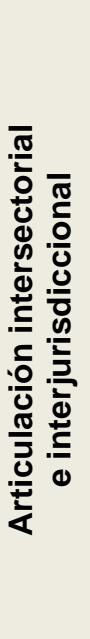 & $\begin{array}{l}\text { La política habitacional tiene que promover una articulación efectiva en cada uno de los niveles } \\
\text { jurisdiccionales, entre los distintos organismos abocados a las políticas sociales, entendidas estas } \\
\text { en sentido amplio, es decir, las políticas de salud, educación, desarrollo social, trabajo, } \\
\text { producción, etc., así como también con las políticas territoriales de desarrollo urbano y rural, } \\
\text { con la finalidad de promover soluciones integrales que tiendan a solucionar los aspectos físicos } \\
\text { del hábitat deficitario, como así también todo lo atinente a integración social de los hogares } \\
\text { afectados por la pobreza. } \\
\text { Con relación a la articulación en el sentido vertical, entre cada uno de los niveles jurisdiccionales } \\
\text { del Estado debe darse una relación de subordinación jerárquica pero concertada desde el } \\
\text { respeto del federalismo y sus autonomías, tendiente a que el gobierno nacional pueda } \\
\text { implementar una política coherente en todo el territorio nacional, a la vez que este respete las } \\
\text { políticas del nivel provincial, como los gobiernos de este nivel y a nivel de los gobiernos } \\
\text { municipales, para que ambos puedan implementar las acciones federales según cómo } \\
\text { consideran el problema en sus respectivas jurisdicciones. }\end{array}$ \\
\hline
\end{tabular}




\begin{tabular}{|c|c|}
\hline 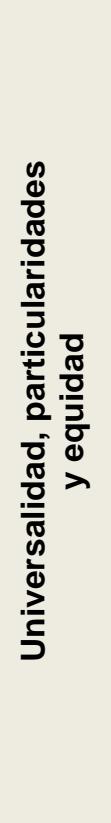 & $\begin{array}{l}\text { Una política habitacional integral tiene que tender a abarcar a todos los hogares que no pueden } \\
\text { acceder por medios propios y de forma permanente a través del mercado formal a condiciones } \\
\text { habitacionales adecuadas para vivir. Este criterio de universalidad tiene que ver con el } \\
\text { reconocimiento de derechos humanos básicos para el conjunto de la población, que presupone } \\
\text { una acción redistributiva amplia, para mejorar las condiciones habitacionales y de vida de toda } \\
\text { la población. A la vez, dado que los que no pueden acceder a una vivienda adecuada por } \\
\text { medios propios conforman un abanico muy amplio de situaciones diferentes, es necesario } \\
\text { identificar situaciones conceptuales tipo que puedan ser abordadas por instrumentos distintos, } \\
\text { que promuevan diferentes articulaciones y funciones entre el Estado, el sector económico } \\
\text { privado, las organizaciones de la sociedad civil y los destinatarios, para hacer más eficientes y } \\
\text { equitativas las inversiones del Estado, y más ajustadas a las necesidades de los diferentes grupos } \\
\text { de destinatarios. Esto implica que las soluciones que proveer por los instrumentos generales de } \\
\text { la política no definan de antemano los medios de satisfacción de las necesidades, sino solo las } \\
\text { líneas de acciones para alcanzar situaciones-metas. Dichos medios serán precisados en cada } \\
\text { caso, en función de diagnósticos participativos y prospectivos, mediante proyectos ajustados a } \\
\text { cada situación. En la definición participativa de las líneas de acción, se tomará como referencia } \\
\text { la situación meta multidimensional de condiciones de vida de los hogares hacia la que se aspira } \\
\text { avanzar progresivamente con cada intervención. }\end{array}$ \\
\hline 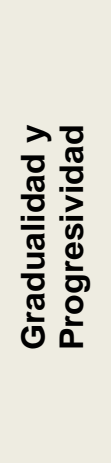 & $\begin{array}{l}\text { Las soluciones de una política habitacional integral que atienda las distintas dimensiones del } \\
\text { problema, que comprendan aspectos tan variados como los de la vivienda o el espacio urbano, } \\
\text { la inserción laboral, la educación, la salud o la protección social, etc., de los miembros de los } \\
\text { hogares, abordados de forma relacionada a través de proyectos integrales, sin dudas implicarán } \\
\text { procesos temporales y de maduración diferentes unos de otros, y en algunos casos inversiones } \\
\text { económicas o de recursos muy divergentes en magnitud. Por lo tanto, es imprescindible } \\
\text { incorporar la idea de que las soluciones, si bien serán productos medibles y cuantificables, se } \\
\text { compondrán de un conjunto de procesos, en algunos casos a largo plazo, y que es necesario } \\
\text { considerarlos desde una perspectiva de gradualidad de los cambios y de progresividad de los } \\
\text { resultados. }\end{array}$ \\
\hline 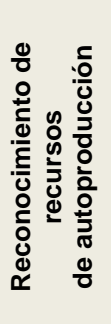 & $\begin{array}{l}\text { Es necesario que a nivel de elaboración de los proyectos, los diagnósticos den cuenta de las } \\
\text { características de los déficits, como así también de los recursos y capacidades de los } \\
\text { destinatarios (los sectores afectados por situación de pobreza, en gran parte autoproducen de } \\
\text { manera precaria su hábitat, y lo hacen siguiendo distintas estrategias, de tipo individual o } \\
\text { colectivas, con diferentes modalidades de organización y a través de recursos muy variados } \\
\text { (económicos, sociales y políticos), con la finalidad de capitalizarlos en la formulación de las } \\
\text { soluciones. }\end{array}$ \\
\hline
\end{tabular}

del cual se considera pertinente, desde el enfoque construido, interpelar a una política habitacional.

El avance en la construcción del marco interpretativo propio para analizar el proceso de configuración de las necesidades habitacionales en las políticas públicas, la vinculación de las teorías de necesidades y las políticas públicas, su adecuación al campo del hábitat social y las políticas habitacionales, puso en evidencia que un abordaje integral del hábitat coherente con la construcción del enfoque de pobreza desde la complejidad, como el que aquí se propicia, requiere un concepto de necesidades habitacionales multidimensionales básicas consensuadas (NHMBC).
Recuperando la cuestión planteada previamente, en relación con el equilibrio entre la universalidad y la particularidad como base de una teoría de las necesidades que sustente la política social y habitacional en particular, se considera que la definición de una cierta cantidad y calidad de NHMBC como válidas en un determinado contexto histórico y cultural operaría como límite al relativismo imperante, que ha favorecido históricamente a la consolidación de las interpretaciones de los grupos hegemónicos y al predominio del enfoque sectorial de las políticas habitacionales. Para ello resulta ineludible avanzar en la visibilización y democratización del proceso de configuración de las necesidades habitacionales, que requiere sin duda 


\begin{tabular}{|c|c|}
\hline 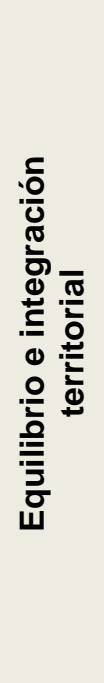 & $\begin{array}{l}\text { La política habitacional debe contribuir con un modelo de desarrollo que promueva un mayor } \\
\text { equilibrio entre las distintas regiones del país y en los territorios provinciales, sobre la base de un } \\
\text { principio de equidad, y priorizar una mayor distribución en regiones y localidades de menor } \\
\text { desarrollo, en pos de propender a un acortamiento de la amplia brecha de los déficits existentes } \\
\text { entre las distintas regiones del país. En la escala urbana, tiene que desalentar la extensión } \\
\text { innecesaria y excesiva de las ciudades, en especial la que se produce de manera discontinua y que } \\
\text { deja grandes predios vacíos dentro de zonas urbanas, para evitar la conformación de ciudades } \\
\text { demasiado extendidas y de baja densidad, que generan muchos recorridos de calles y grandes } \\
\text { superficies de espacios públicos que tornan insustentable para los municipios brindar servicios } \\
\text { públicos. La política habitacional tiene que contribuir con modelos de ciudades más compactas; } \\
\text { promover la densificación a través de los mejoramientos de las áreas deficitarias críticas y la } \\
\text { ocupación de los predios vacíos intersticiales; propiciar la generación de un círculo más virtuoso } \\
\text { entre el mejoramiento de las redes de infraestructuras básicas, los equipamientos sociales de } \\
\text { salud, educación, cultura, recreación, esparcimiento, seguridad, etc., y el mejoramiento de los } \\
\text { servicios, en pos de una mejor y más sustentable calidad de vida. }\end{array}$ \\
\hline 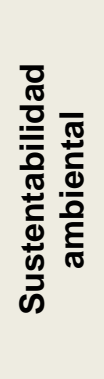 & $\begin{array}{l}\text { La política habitacional debe alinearse con una política de cobertura más extensa, como es la de } \\
\text { la protección y gestión sustentable del medio ambiente, que en rigor es una obligación } \\
\text { constitucional en Argentina (Art. 41). Si bien la cuestión comenzó a ser reconocida en textos } \\
\text { oficiales, en los hechos no ha sido en absoluto incorporada a la política de hábitat social. } \\
\text { La implementación de esta premisa constitucional implicaría, en el marco de una política } \\
\text { habitacional integral, que tanto las acciones de producción como las de uso cotidiano de los } \\
\text { bienes y servicios que constituyen la vivienda estén sujetos a la consigna de daño mínimo o daño } \\
\text { cero del medio ambiente, y de un intercambio equitativo entre este y el hábitat humano. }\end{array}$ \\
\hline 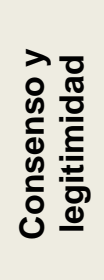 & $\begin{array}{l}\text { La intervención del Estado en materia habitacional debe superar el rango de acciones } \\
\text { gubernamentales transitorias y constituirse en una función indelegable y permanente. Para ello es } \\
\text { imprescindible que el Estado disponga de un marco jurídico estructural, resultante de un amplio } \\
\text { acuerdo entre los diferentes agentes políticos, económicos y sociales, que además de brindar } \\
\text { consenso social y legitimidad institucional a las acciones de un gobierno, asegure su estabilidad } \\
\text { en tiempo, bajo la custodia de la ciudadanía. }\end{array}$ \\
\hline 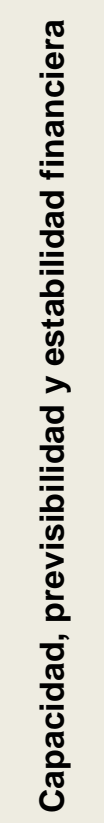 & $\begin{array}{l}\text { El marco jurídico que regule la intervención estructural del Estado en el campo habitacional debe } \\
\text { prever una fuente de financiamiento permanente, que garantice de forma sustentable los } \\
\text { recursos económicos necesarios para la implementación constante de la política habitacional, } \\
\text { mediante su incorporación permanente en el presupuesto de inversiones del Estado. } \\
\text { La fuente de financiamiento permanente debe ser sustentable y nutrirse de ingresos genuinos del } \\
\text { Estado (sin generar endeudamiento), y debe ser eficiente en su retroalimentación mediante } \\
\text { recuperos adecuados a la capacidad de pago de los diferentes sectores sociales, además de } \\
\text { contemplar el subsidio solamente en casos de extremas necesidades. Por otra parte, debe ser } \\
\text { suficiente para resolver el problema del conjunto de la población deficitaria en un período } \\
\text { razonable. Debe también disponer de reglas explícitas de distribución equitativa entre las distintas } \\
\text { jurisdicciones, en proporción a sus déficits socio-habitacionales, y sus recursos deben ser de } \\
\text { accesibilidad automática por parte de las jurisdicciones, con mecanismos de contralor sobre sus } \\
\text { usos eficientes. Asimismo debe garantizar y estimular la participación de los diferentes sectores } \\
\text { involucrados en la producción habitacional. }\end{array}$ \\
\hline
\end{tabular}


Una política habitacional integral debe contemplar el desarrollo de capacidades institucionales, organizativas y en recursos humanos, en los tres niveles jurisdiccionales del Estado, para poder formular e implementar medidas que contemplen también la participación de una mayor diversidad de actores y modalidades productivas.

Desde una política habitacional integral se debería promover la participación equilibrada de las diferentes modalidades productivas de las soluciones, dar participaciones equivalentes a las empresas de organización capitalistas y a las organizaciones productivas de tipo social, como las cooperativas, los sistemas de ayuda mutua, de autoconstrucción asistida o construcción realizada bajo la administración de los destinatarios, según las características de los casos para ser solucionados.

La producción habitacional promovida por la política habitacional debe insertarse y promover estrategias de desarrollo local en las diferentes localidades. Desde esta perspectiva se entiende como desarrollo local a una estrategia que trata de utilizar los factores internos y externos que surgen en los procesos de cambio estructural de la economía para promover el desarrollo de una localidad, provincia o región. Se basa en que cada comunidad dispone de un conjunto de recursos (económicos, humanos, culturales, institucionales) que constituyen un potencial de desarrollo endógeno.

옹

La política habitacional integral debe reconocer un umbral básico universal deseable en el conjunto de factores que hacen a sus condiciones de vida como meta de una intervención integral de estas áreas. Para este umbral mínimo deseable universal se propone aquí el concepto de Hábitat Digno. ${ }^{11}$

Fuente: elaboración propia con base en BARRETO et ÁL. (2014)

un fuerte protagonismo del Estado en este proceso, promoviendo la participación de diversos actores políticos, comunitarios, económicos, académicos, etc., mitigando las imposiciones que algunos sectores puedan ir logrando sobre otros, en pos de lograr una distribución equitativa de la participación para el establecimiento de consensos, integrando la dimensión colectiva o social de las necesidades (DUBOIS MIGOYA, 2008).

En cuanto a los lineamientos de una política habitacional integral desarrollados previamente, se considera que pueden ser un aporte significativo, sobre la base del cual —en el marco de la visibilización y democratización del proceso de configuración de las necesidades habitacionales - se defina una cierta cantidad y calidad de NHMBC, que resultan imprescindibles para superar las profundas inequidades producidas por la forma en que el proceso se ha dado históricamente. El reconocimiento de un conjunto de NHMBC implica la prestación por parte del Estado de ciertas coberturas universales básicas en relación con la problemática en cuestión, que abarquen al conjunto de la población de manera general, es decir, que tengan las características de derechos ciudadanos, sin discriminación alguna, pero que contemple la implementación de coberturas particulares para los casos de mayor exclusión. Avanzar en esta cuestión implica la necesidad de diseñar procesos de construcción de políticas habitacionales que permitan — por sí mismas o través de la articulación con otras políticas sociales- equiparar las "precondiciones sociales" (DOYAL Y GOUGH, 1991) de los individuos para que accedan a la satisfacción de las NHMBC.

Sin dudas, la definición de un conjunto de NHBMC que aquí se promueve requiere en primer término avanzar en la visibilización y democratización de su proceso de configuración. En esto se considera imprescindible que el Estado - como poseedor de un metacapital (BOURDIEU, 1993) - asuma un rol protagónico, orientado a lograr una distribución equitativa de la participación de los diferentes sectores económicos y sociales organizados de la sociedad, y en particular de los destinatarios de las soluciones para el establecimiento de consensos, integre la ya mencionada dimensión colectiva o social de las necesidades, y asuma que un proceso de configuración de las necesidades como el que aquí se propone debe combinar el derecho a satisfacer las necesidades con el derecho a participar en las decisiones de cómo alcanzar esa realización (KRMPOTIC, 1999 y GOUGH, 2003).

En relación con los satisfactores adecuados a la perspectiva de las NHBMC, se entiende que el concepto

11 Este concepto engloba la vivienda digna junto a otros factores que en conjunto constituyen un umbral básico deseable de calidad de vida de todos los hogares. 
de "necesidades intermedias" o "características universales de los satisfactores" de DOYAL Y GOUGH (1991) permitiría cubrir la brecha entre necesidades universales y satisfactores variables, cuestión que haría viable -como estrategia de formulación de una política habitacional integral- pensar en un conjunto de alternativas o variadas formas de satisfacer una necesidad habitacional, entre las que los destinatarios pudieran elegir, en reemplazo de los satisfactores predefinidos y estandarizados que las políticas habitacionales han concebido históricamente en Argentina. Se suscribe además que los satisfactores ofrecidos por una política habitacional a través de sus instrumentos operativos (programas y proyectos) deben ser "satisfactores sinérgicos" (MAX NEFF, ELIZALDE y HOPPENHAYN, 1986), caracterizados por satisfacer una determinada necesidad estimulando y contribuyendo simultáneamente a la satisfacción de otras, ya que se entiende que el problema habitacional de los sectores afectados por situaciones de pobreza es complejo y no se soluciona atacando únicamente los aspectos físicos del hábitat, ya que en su determinación intervienen aspectos muy variados, que requieren ser identificados y tratados conjuntamente como dimensiones de un mismo problema para dar una respuesta integral.

\section{CONCLUSIONES O REFLEXIONES FINALES}

Los aportes teóricos analizados y las propias construcciones conceptuales que se han ido vertiendo pueden sintetizarse en un conjunto de directrices o lineamientos específicos para una política habitacional integral fundada en una teoría de las NHBMC. (Ver cuadro 2). Finalmente, cabe señalar que la revisión exhaustiva del estado del arte posibilitó avanzar en la construcción de un marco interpretativo propio, con el objeto de conformar un corpus conceptual crítico a la luz del cual analizar el proceso de configuración de las necesidades habitacionales en las políticas públicas y contribuir al desarrollo de una teoría de necesidades habitacionales básicas multidimensionales consensuadas (NHBMC) como fundamento de una política habitacional integral. 
Cuadro 2. Lineamientos específicos para una política habitacional fundada en una teoría de las NHBMC

\begin{tabular}{|c|c|}
\hline $\begin{array}{l}\text { Equilibrio entre } \\
\text { universalidad y } \\
\text { particularidad }\end{array}$ & $\begin{array}{l}\text { Como base de una teoría de las necesidades que sustente la política } \\
\text { social y habitacional en particular. }\end{array}$ \\
\hline $\begin{array}{l}\text { Reconocimiento de un } \\
\text { conjunto de necesidades } \\
\text { habitacionales } \\
\text { multidimensionales } \\
\text { básicas consensuadas }\end{array}$ & $\begin{array}{l}\text { Implica la prestación por parte del Estado de ciertas coberturas } \\
\text { universales básicas en relación con la problemática en cuestión, que } \\
\text { abarquen al conjunto de la población de manera general, es decir, que } \\
\text { tengan las características de derechos ciudadanos. A su vez se asume el } \\
\text { requerimiento de implementar coberturas particulares para los casos de } \\
\text { mayor exclusión (equilibrio entre universalidad y particularidad). }\end{array}$ \\
\hline $\begin{array}{l}\text { Definición de las } \\
\text { "necesidades intermedias" } \\
\text { o "características } \\
\text { universales } \\
\text { de los satisfactores" }\end{array}$ & $\begin{array}{l}\text { Implica y permite el equilibrio entre necesidades universales y } \\
\text { satisfactores variables, pensar en un conjunto de alternativas o variadas } \\
\text { formas de satisfacer una necesidad habitacional, entre las que los } \\
\text { destinatarios pudieran elegir, en reemplazo de los satisfactores } \\
\text { predefinidos y estandarizados que las políticas habitacionales ha } \\
\text { concebido históricamente en Argentina y en el AMGR. }\end{array}$ \\
\hline $\begin{array}{l}\text { Promoción de satisfactores } \\
\text { sinérgicos }\end{array}$ & $\begin{array}{l}\text { Caracterizados por satisfacer una determinada necesidad estimulando y } \\
\text { contribuyendo simultáneamente a la satisfacción de otras. }\end{array}$ \\
\hline $\begin{array}{l}\text { Visibilización y } \\
\text { democratización del } \\
\text { proceso de configuración } \\
\text { de las necesidades } \\
\text { habitacionales }\end{array}$ & $\begin{array}{l}\text { Requiere sin dudas un fuerte protagonismo del Estado, que promueva la } \\
\text { participación de diversos actores políticos, comunitarios, económicos, } \\
\text { académicos, etc., mitigue las imposiciones que algunos sectores puedan } \\
\text { ir logrando sobre otros, en pos de lograr una distribución equitativa de } \\
\text { la participación para el establecimiento de consensos; integre la } \\
\text { dimensión colectiva o social de las necesidades y combine el derecho a } \\
\text { satisfacer las necesidades con el derecho a participar en las decisiones de } \\
\text { cómo alcanzar esa realización. }\end{array}$ \\
\hline $\begin{array}{l}\text { Concepción del problema } \\
\text { habitacional de los } \\
\text { sectores afectados por } \\
\text { situaciones de pobreza } \\
\text { desde la complejidad }\end{array}$ & $\begin{array}{l}\text { Implica entender que este no se soluciona atacando únicamente los } \\
\text { aspectos físicos del hábitat, ya que en su determinación intervienen } \\
\text { aspectos muy variados de naturaleza económica, social, cultural, } \\
\text { ambiental, etc., tales como la educación, la salud, la marginación física, } \\
\text { social y cultural, los riesgos ambientales, la inseguridad, los derechos } \\
\text { civiles y políticos, las diferencias de géneros, edades y etnias, e incluso } \\
\text { sus formas subjetivas de percepción, etc., que requieren ser identificados } \\
\text { y tratados conjuntamente como dimensiones de un mismo problema } \\
\text { para dar una respuesta integral. Por el contario, se entiende que una } \\
\text { política habitacional integral requiere como fundamento una teoría de } \\
\text { NHBMC construidas en un proceso de mayor democratización con un } \\
\text { fuerte protagonismo del Estado. }\end{array}$ \\
\hline
\end{tabular}




\section{BIBLIOGRAFIAA}

BARRETO, Miguel Á.; ALCALÁ, Laura; BENÍTEZ, María A.; FERNÁNDEZ, María E.; GIRÓ, Marta; PELLI, María B. y ROMAGNOLI, Venettia. Colab: DEPETRIS, Noel (2014) La política Federal de Vivienda desde su implementación en el Gran Resistencia (2003-2007). Análisis y recomendaciones. Diseño. 1.a ed. Buenos Aires.

BARRETO, M. y LENTINI, M. (coordinadores) (2014) Hacia una política integral de hábitat. Aportes para un observatorio de política habitacional en Argentina. Editorial Café de las ciudades, Bs. As.

BARRETO, Miguel A. y ALCALÁ, Laura I. (2008). "Cambios en las prestaciones urbano-ambientales de la política habitacional argentina. Reflexiones a partir de cuatro programas orientados a población en situación de pobreza del Gran Resistencia". En: Sepúlveda Ocampo, Rubén (Coord.), V Jornada Internacional de Vivienda Social. El derecho a la ciudad y la vivienda. Propuestas y desafíos en la realidad actual. Ed. Instituto de la Vivienda, Facultad de Arquitectura y Urbanismo, Universidad de Chile, Santiago. (pp. 51-63) ISBN 978-956-19-0589-4.

BOURDIEU, Pierre (1998). La Distinción. Criterio y bases sociales del gusto. Taurus Ediciones, Madrid.

DOYAL, Len y GOUGH, Ian (1994) Teoría de las necesidades humanas. Icaria, Barcelona.

DUBOIS MIGOYA, Alfonso (2008). "El debate sobre el enfoque de las capacidades: las capacidades colectivas". Araucaria. Vol. 10, Núm. 20, pp. 35-63. Universidad de Sevilla, España.

FRASER, Nancy (1986). Movimientos sociales vs. Burocracias disciplinarias: los discursos de las necesidades sociales. Center for Humanistic Studies, University of Minnesota.

FRASER, Nancy (1997) lustitia Interrupta: Reflexiones críticas desde la posición "postsocialista". Santafé de Bogotá, Siglo del Hombre Editores, Universidad de los Andes.

FRASER, Nancy (1991). "La lucha por las necesidades: esbozo de una teoría crítica socialistafeminista de la cultura política del capitalismo tardío". En: Revista Debate Feminista. Marzo, 1991.

GOUGH, Ian (2008). "Nussbaum: un análisis comparado con nuestra teoría de las necesidades humanas". En: Papeles de Relaciones Ecosociales y Cambio Global. N. ${ }^{\circ}$ 100, CIP-Ecosocial/lcaria, invierno 2007/08.

GOUGH, Ian (2003) Capital global, necesidades básicas y políticas sociales. Ed. Miño Davila-Ciepp, Bs. As.

HELLER, Ágnes (1996) Una revisión de la teoría de las necesidades. Paidós e ICE de la Universidad Autónoma de Barcelona, Barcelona, España.

HELLER, Ágnes (1986) Teoría de las necesidades en Marx. Península. Barcelona, España.

JONES, Ch. O. (1984) An Introduction torhe Study of Public Policy. Monterrey, CA., Brooks/Cole Publishing Company.

KRMPOTIC, Claudia (1999). El concepto de necesidad y políticas de bienestar. Una lectura comparada de Heller, Sen y el GPID. Espacio editorial, Buenos Aires, Argentina.

MASLOW, Abraham (1954) Motivation And Personality. Harper, New York.

MAX-NEEF, Elizalde y OPENHAYN (1986) Desarrollo a escala humana. Chile: CEPAUR y Suecia: Fundación Dag Hammarskjold.

PELLI, Víctor S. (2006) Habitar, Participar, Pertenecer. Acceder a la vivienda, incluirse en la sociedad. Nobuko, Buenos Aires.

PEREIRA, POTYARA A. (2002) Necesidades Humanas. Para una crítica a los patrones mínimos de sobrevivencia. Cortez Editora, San Pablo, Brasil.

ROMAGNOLI, Venettia (2012). "La configuración de las necesidades en las políticas habitacionales a partir del caso del AMGR (Chaco)". En: XXXII Encuentro de Geohistoria Regional. Libro de Actas. Resistencia, 19, 20 y 21 de agosto de 2011. Enrique Schaller, María del Mar Solís Carnicer y Norberto Lanza (coord). Rcia., Instituto de Investigaciones Geohistóricas, CONICET- UNNE, 2011. ISBN 978-987-28041-1-4. pp. 429- 440. SUBIRATS, Joan (1989). Análisis de las políticas públicas y eficacia de la administración. Instituto Nacional de Administración Pública, Madrid. TAMAYO SÁEZ, Manuel (1997). "El análisis de las políticas públicas" En: Bañón, Rafael y Carrillo, Ernesto (compiladores). La nueva administración pública. Alianza Universidad, Madrid.

YUJNOVSKY, Oscar (1984) Claves Políticas del Problema Habitacional Argentino 1955/1981. Grupo Editor Latinoamericano SRL. Buenos Aires, Argentina. ISBN 950-9432-00-8. 